See Article page 308.

\section{Commentary: A picture is worth a thousand words, but only tells one story}

\author{
Joseph R. Nellis, MD, MBA, a,b \\ Nicholas D. Andersen, MD, ${ }^{\mathrm{a}, \mathrm{b}, \mathrm{c}}$ and \\ Joseph W. Turek, MD, PhD, MBA ${ }^{\mathrm{a}, \mathrm{b}, \mathrm{c}}$
}

If done slowly, the initial heating curve for water is linear. It is a predictable relationship. And, without prior knowledge, it wouldn't be unreasonable to think that it goes on, one-forone, well beyond $100^{\circ} \mathrm{C}$. But we know this isn't true. Like many things in science and life, the past does not always predict the future.

In this issue of JTCVS Open, Hameed and colleagues ${ }^{1}$ provide in-depth analysis of their novel hybrid stage II repair for select patients with hypoplastic left heart syndrome using computational fluid dynamic (CFD) modeling. Based on representative patient imaging, they were able to create virtual models of the repair and interrogate the hemodynamic implications of $H$, or the distance between the anterior main pulmonary artery and the anterior baffle. The team concluded that the repair is hemodynamically sound based on an estimated pressure loss over the baffle of less than $10 \mathrm{~mm} \mathrm{Hg}$, a Reynolds coefficient of less than 2000 , and a clinically insignificant vortex shedding distance. As a standalone report, we would agree with their assessment, although having read their clinical case series, we have some reservations. ${ }^{2}$ Over a 6 -year period, 4 patients underwent a hybrid stage II repair. One died due to a pulmonary embolism, and the other 3 ultimately required an estimated 19 cardiac catheterizations, 13 balloon angioplasties, and 13 stents.

\footnotetext{
From the ${ }^{\mathrm{a} D u k e}$ Congenital Heart Surgery Research \& Training Laboratory, and ${ }^{\mathrm{b}}$ Department of Surgery, Duke University Hospital; and ' Duke Children's Pediatric \& Congenital Heart Center, Duke Children's Hospital, Durham, NC.

Disclosures: The authors reported no conflicts of interest.

The Journal policy requires editors and reviewers to disclose conflicts of interest and to decline handling or reviewing manuscripts for which they may have a conflict of interest. The editors and reviewers of this article have no conflicts of interest.

Received for publication June 3, 2021; revisions received June 3, 2021; accepted for publication June 24, 2021; available ahead of print July 23, 2021.

Address for reprints: Joseph W. Turek, MD, PhD, MBA, Division of Thoracic and Cardiovascular Surgery, Duke University Medical Center, 2301 Erwin Rd, DUMC 3474, Durham, NC 27710 (E-mail: joseph.turek@ duke.edu).

JTCVS Open 2021;7:325-6

2666-2736

Copyright (c) 2021 The Author(s). Published by Elsevier Inc. on behalf of The American Association for Thoracic Surgery. This is an open access article under the CC BY-NC-ND license (http://creativecommons.org/licenses/by-nc-nd/4.0/).

https://doi.org/10.1016/j.xjon.2021.06.028
}

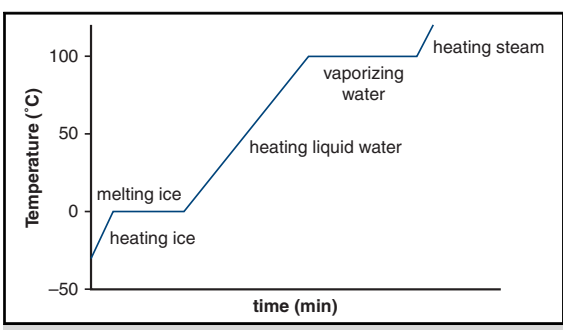

The heating curve for water is not a linear relationship with regards to time.

\section{CENTRAL MESSAGE \\ The past does not always predict the future. And while attractive, CFD models should be cautiously interpreted in the face of con- tradictory clinical outcomes.}

While their model is accurate and the math is sound, "Computational Fluid Dynamic Investigation of the Novel Hybrid Comprehensive Stage II Operation" highlights how inductive reasoning can lead us astray. CFD can quickly turn into a foreign language for those of us without strong engineering backgrounds. It is intimidating. Our default, to downplay our lack of understanding, is to accept everything at face value. However, as surgeons we can see the disconnect in these related, although independent, conclusions, highlighting one of the most important points about CFD_it is an $n$ of 1 at time zero. Generally speaking, although Hameed and colleagues ${ }^{1}$ adjusted $H$ and explored the sensitivity of their model to surgical and patient variability, the model continues to represent one time point. It isn't wrong, but like a happy turkey on the farm, Thanksgiving Day still comes, and eventually the model falls apart. CFD has a role in cardiac surgery, and with time we're confident it will find its place. ${ }^{3-5}$ In the meantime, when making decisions, we should be cautious about the relative weight we give theoretical models when faced with contradictory clinical outcomes. The past does not always predict the future, particularly when it's built on assumptions.

\section{References}

1. Hameed M, Prather R, Divo E, Kassab A, Nykanen D, Farias M, et al. Computational fluid dynamics investigation of the novel hybrid comprehensive stage II operation. J Thorac Cardiovasc Surg Open. 2021;7:308-23.

2. Farias M, Fleishman CE, Nykanen D, DeCampli WM. Clinical update on the hybrid comprehensive stage II operation. J Thorac Cardiovasc Surg Open. 2021;7:327-35. 
3. Capelli C, Sauvage E, Giusti G, Bosi GM, Ntsinjana H, Carminati M, et al. Patientspecific simulations for planning treatment in congenital heart disease. Interface Focus. 2018;8:20170021.

4. Hohri Y, Itatani K, Yamazaki S, Yaku H. Computerized virtual surgery based on a computational fluid dynamics simulation for planning coronary revascularization with aortic root replacement in adult congenital heart disease: a case report. Gen Thorac Cardiovasc Surg. 2021;69:722-6.

5. Nellis JR, Chung TK, Agarwal N, Torres JE, Holgren SE, Raghavan ML, et al. Modeling outcomes: modified aortic arch advancement for neonatal hypoplastic arch. Innovations (Phila). 2017;12:109-15. 